\title{
Mechanical Properties of Cu/Ta Multilayers Prepared by Magnetron Sputtering
}

\author{
Tai D. Nguyen \\ Troy W. Barbee, Jr.
}

This paper was prepared for submittal to the

Materials Research Society

San Francisco, CA

April 13-16, 1998

April 1998

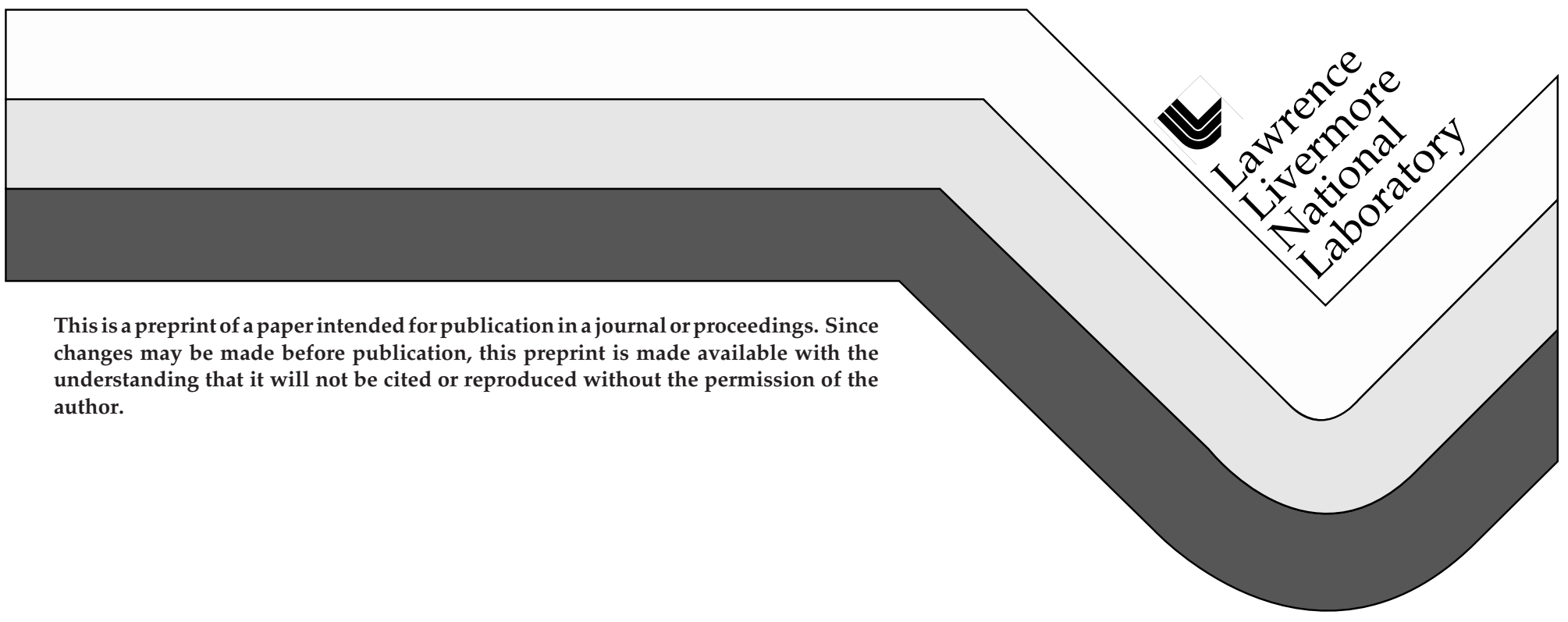




\section{DISCLAIMER}

This document was prepared as an account of work sponsored by an agency of the United States Government. Neither the United States Government nor the University of California nor any of their employees, makes any warranty, express or implied, or assumes any legal liability or responsibility for the accuracy, completeness, or usefulness of any information, apparatus, product, or process

disclosed, or represents that its use would not infringe privately owned rights. Reference herein to any specific commercial product, process, or service by trade name, trademark, manufacturer, or otherwise, does not necessarily constitute or imply its endorsement, recommendation, or favoring by the United States Government or the University of California. The views and opinions of authors expressed herein do not necessarily state or reflect those of the United States Government or the University of California, and shall not be used for advertising or product endorsement purposes. 


\title{
MECHANICAL PROPERTIES OF Cu/Ta MULTILAYERS PREPARED BY MAGNETRON SPUTTERING
}

Tai D. Nguyen and Troy W. Barbee, Jr., Chemistry and Materials Science Department, Lawrence Livermore National Laboratory, Livermore, CA 94550.

\begin{abstract}
The microstructure and mechanical properties of sputtered $\mathrm{Cu} / \mathrm{Ta}$ multilayers were studied. Xray diffraction and transmission electron microscopy characterization indicate that both the Ta and $\mathrm{Cu}$ in the $2 \mathrm{~nm}$ period multilayer are predominantly amorphous, while in longer period samples, the layers are crystalline, with the metastable tetragonal $\beta$-Ta observed. No observable microstructure changes upon annealing at $300^{\circ} \mathrm{C}$ were found. An average Vickers micro-hardness value of about $5.5 \mathrm{GPa}$ was measured, which increases about $5 \%$ upon annealing at $300^{\circ} \mathrm{C}$. Residual stress in the multilayers and its dependence on thermal annealing are reported. The relationships between microstructure and mechanical properties in the multilayers are discussed.
\end{abstract}

\section{INTRODUCTION}

Multilayers composed of nanometer layer thicknesses have shown enhanced mechanical properties and are thus candidates for wear resistant coating applications. The mechanical properties depend on the component materials properties, processing conditions, microstructure, and interfacial structure in the multilayers. Interfacial structure and reactions become important as the thicknesses of the component layers approach the dimension of the interfaces. In this research, we investigate the effects of the materials properties of the layer constituents in the multilayers, in particular their thermodynamic and kinetic properties, and of post deposition treatments on the mechanical properties of the multilayers. Two thermodynamically different systems were chosen: materials pairs that are immiscible to each other, and pairs that react to form compounds in equilibrium conditions. In this paper, we present the results for an immiscible system, $\mathrm{Cu} / \mathrm{Ta}$ multilayers, with bilayer periods ranging from 2 to 200 nanometers.

$\mathrm{Cu} / \mathrm{Ta}$ is a technologically interesting system for a variety of reasons. It has been applied in $\mathrm{x}-$ ray optics, and is being considered as a potential barrier for $\mathrm{Cu}$ metallization process in electronic devices. $^{1-2}$ Thermodynamically, $\mathrm{Cu}$ and Ta are immiscible and the binary system is characterized by a positive heat of mixing. The equilibrium phase diagram does not show the presence of any solid solution nor intermetallic compound. An amorphous phase of $\mathrm{Cu}-\mathrm{Ta}$ alloys however has been obtained by either co-sputtering ${ }^{3}$ or ball mill mechanical alloying of the elemental powders. ${ }^{4-5}$.

Growth, structure, and properties of $\mathrm{Ta}$ and $\mathrm{Cu}$ single films have been studied extensively. Two different structures, the equilibrium $\alpha$-BCC phase and the metastable $\beta$-phase tetragonal, have been reported in thick $(>2.5 \mathrm{~nm})$ sputtered Ta films and depend on deposition conditions and film thickness. ${ }^{2,6-10}$ Also, residual stresses in Ta thin films have been found to vary with film thickness and deposition parameters. ${ }^{8-12}$ Thin Ta films are compressive; while films at thicknesses between 10 and $50 \mathrm{~nm}$ are tensile. ${ }^{9-10}$ This stress transition is attributed to the transformation from an amorphous phase to the $\beta$ crystalline phase between 2.5 and $20 \mathrm{~nm}$ film thickness. ${ }^{9-10}$ Stress in sputtered films of $100 \mathrm{~nm}$ thick grown on oxidized Si wafers were found to be highly compressive at low pressure, and tensile at high pressure. ${ }^{2,6-8}$ Annealing of the compressive tetragonal Ta single films lead to stress relaxation whose mechanisms include plastic deformations at moderate temperatures, and the tetragonal- $\beta$ to $\mathrm{BCC}-\alpha$ phase transition at temperatures between $600^{\circ}$ and $800^{\circ} \mathrm{C} .^{8}$ 
Studies of $\mathrm{Cu} / \mathrm{Ta}$ multilayers, however, are few. Reports in the literature have focused on the microstructure of the layers. ${ }^{11-12}$ The Ta in multilayers prepared by electron beam evaporation has the equilibrium BCC structure. ${ }^{11}$ Sputtering of $\mathrm{Ta} / \mathrm{Cu}$ multilayers with Ta layer thickness up to $10 \mathrm{~nm}$ produces the metastable tetragonal $\beta$-Ta structure with a preferred $\langle 002\rangle$ growth orientation. $^{12}$ Annealing of $\mathrm{Cu} / \mathrm{Ta} / \mathrm{Cu}$ trilayers results in a re-orientation of textured $<002>$ tetragonal Ta to $\langle 202\rangle \mid\langle 211\rangle$, an of the $\beta$-tetragonal to the equilibrium $\mathrm{BCC}$ structure. In this paper, we report the preliminary results on the hardness, and residual stress, and their dependence on thermal annealing in sputtered $\mathrm{Cu} / \mathrm{Ta}$ multilayers.

\section{EXPERIMENTAL TECHNIQUES}

The multilayers were deposited by dc-magnetron sputtering onto 4" $\mathrm{Si}$ wafers. The base pressure of the chamber was in the $10^{-7}$ Torr range, and the sputtering gas was Ar at $2 \mathrm{mT}$ pressure. The period of the multilayers studied ranges from 2 to 200 nanometers, with equal thickness of $\mathrm{Cu}$ and Ta layers. The number of bilayer pairs in the multilayers was varied so that the total thickness of these films is approximately 25 microns. Thick films of elemental $\mathrm{Cu}$ and $\mathrm{Ta}$ of sequentially deposited $10 \mathrm{~nm}$ thick layers were also synthesized as base-line structure. For annealing studies of the residual stress, $\mathrm{Si}$ wafers coated with an approximately $600 \mathrm{~nm}$ thick thermal oxide film were used to avoid silicide reactions during annealing. The first and last layers in all the multilayers were Ta, and the sample with the shortest period $(2 \mathrm{~nm})$ was also coated with an additional $2 \mathrm{~nm}$ of Ta as a capping layer.

The structures were studied by low- and high-angle x-ray diffraction, and cross-sectional and plan-view transmission electron microscopy (TEM). The x-ray diffraction measurements were performed using a Rigaku x-ray diffractometer and $\mathrm{Cu} \mathrm{K}_{\alpha}$ radiation. The TEM specimens were prepared by mechanical grinding and dimpling followed by ion milling. They were then examined in a Topcon 002B $200 \mathrm{kV}$ high-resolution electron microscope, at the National Center for Electron Microscopy, Lawrence Berkeley National Laboratory. Residual stress measurements were made using a commercial Tencor (KLA) laser-scanning wafer curvature measurement apparatus. In-situ stress measurement during annealing was performed on a covered hot plate with a $\mathrm{N}_{2}$ flow for isolation. A heating rate of $5^{\circ} \mathrm{C} /$ minute and a cooling rate of $10^{\circ} \mathrm{C} /$ minute were used. Vickers hardness tests were performed at 50 gram and 100 gram loads normal to the layering for films on the silicon substrates and removed from the Si substrates. Hardness was measured both on the top layers, and on the layers near the substrate of the multilayers removed from the substrates.

\section{RESULTS AND DISCUSSION}

Structure and phases:

Low angle x-ray diffraction scans of the as-deposited and annealed 2 and $5 \mathrm{~nm}$ period multilayers are shown in Figure 1. The modulation apparent in the scan background arises from the approximately $3 \mathrm{~nm}$ thick Ta layer on top of these short period multilayers. The intense low angle Bragg's peaks indicate strong compositional modulation in both the as-deposited and annealed samples. Essentially no effects due to annealing at $300^{\circ} \mathrm{C}$ are apparent in the Figure.

High angle $\mathrm{x}$-ray diffraction scans of the multilayers were performed to study thickness dependence of individual layer structures and microstructure evolution in the multilayers as the period varied. Figure 2 shows the high angle diffraction patterns of the multilayers with period from $2 \mathrm{~nm}$ to $200 \mathrm{~nm}$, and of the elemental Ta and $\mathrm{Cu}$ films. The Ta film has peaks at $33.7^{\circ}$ and $70.8^{\circ}$ in $2 \Theta$, which correspond to the first and second orders of the 002 metastable $\beta$-tetragonal Ta structure. The $\mathrm{Cu}$ film shows preferred FCC 111 and 200 growth orientations. The $\mathrm{Cu}$ layers in the $5 \mathrm{~nm}$ period multilayer sample (approximately $2.5 \mathrm{~nm} \mathrm{Cu}$ layer thick) and larger grow 
preferentially in the 111 direction $\left(2 \Theta=43.3^{\circ}\right)$, with an increasing 200 peak $\left(2 \Theta=50.4^{\circ}\right)$ starting at $100 \mathrm{~nm}$ period, and a 220 peak $\left(2 \Theta=74.1^{\circ}\right)$ in the $200 \mathrm{~nm}$ period sample. The $2 \mathrm{~nm}$ period sample shows a broad peak, and a shoulder at a lower angle, at an intermediate position between the $111 \mathrm{FCC} \mathrm{Cu}$ and one of the Ta peaks. This broad peak is characteristic of a preminantly amorphous phase. In longer period samples the tetragonal Ta phase, with a dominant 002

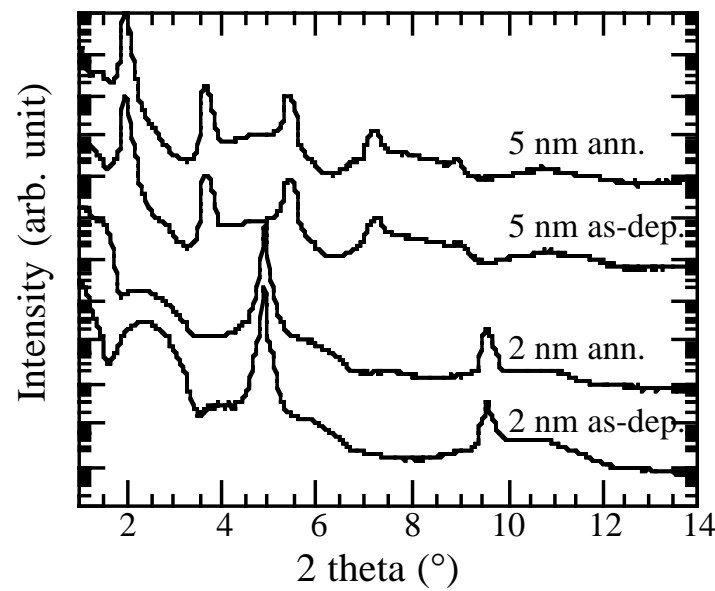

broad peak at a position near that of the 110 BCC Ta peak $\left(2 \Theta=38.5^{\circ}\right)$ and also the 202 $\left(2 \Theta=38.3^{\circ}\right)$ and 211

Figure 1. Low angle x-ray diffraction scans of as-deposited and annealed $2 \mathrm{~nm}$ and $5 \mathrm{~nm}$ period multilayers showing that essentially no effects due to annealing at $300^{\circ} \mathrm{C}$ are apparent.

Figure 2. High angle x-ray diffraction scans of and 202/211 growth orientations along with other tetragonal peaks, was observed. A

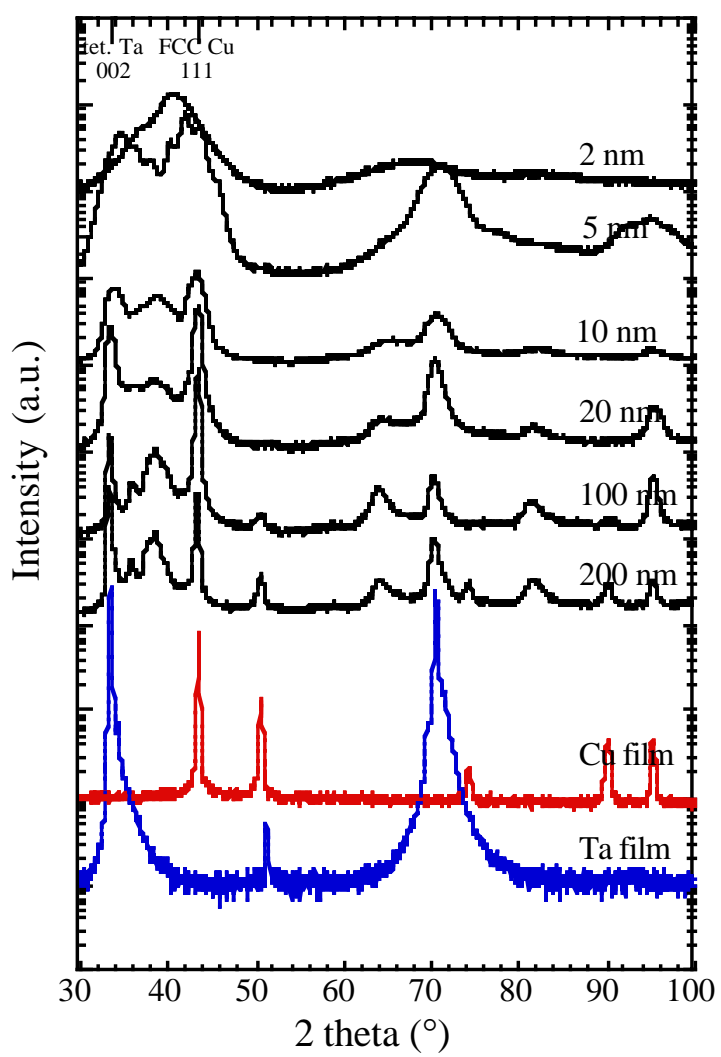

the $\mathrm{Cu}$ and $\mathrm{Ta}$ single films and multilayers.

Peaks of the FCC Cu and the metastable tetragonal- $\beta$ Ta structures are present. Satellite peaks of the $\mathrm{Cu}$ and Ta lattices are observed in the 5 and $10 \mathrm{~nm}$ period multilayers indicating uniform periodicity.

$\left(2 \Theta=38.8^{\circ}\right)$ peaks of the tetragonal phase in the $10 \mathrm{~nm}$ period sample is observed to grow with increasing period of the multilayers. This peak could not be identified conclusively with either structure, though studies by other researchers by $\Psi$-scans concluded that the peak at this position in their samples correspond to the tetragonal structure. ${ }^{12}$ Satellite peaks of the $\mathrm{Cu}$ and Ta lattices are observed in the $5 \mathrm{~nm}$ and $10 \mathrm{~nm}$ period samples, which suggest a defined periodicity in the multilayers. High angle x-ray diffraction scans of the samples annealed at $300^{\circ} \mathrm{C}$ indicate that no change from the as-deposited state occurred. The scan of the annealed $2 \mathrm{~nm}$ period sample has the broad peak at an intermediate position between the $\mathrm{Cu}$ and Ta peaks, similar to that in the asdeposited sample. The longer period samples show the peaks corresponding to the tetragonal Ta 
structure, and the FCC $111 \mathrm{Cu}$ peak. The FCC $111 \mathrm{Cu}$ peak in the scan of the $5 \mathrm{~nm}$ period sample shifts closer to the bulk value upon annealing.

A cross-sectional bright-field TEM image of the $2 \mathrm{~nm}$ period multilayer sample and its diffraction pattern are shown in Figure 3. The layers are seen to be continuous and uniform. A few crystallites 1-2 $\mathrm{nm}$ in diameter are observed in both the $\mathrm{Cu}$ and Ta layers. The diffraction pattern shows the large spacing modulation spots near the direct beam arising from the multilayer periodicity, and a diffuse halo indicative of an amorphous structure having an average inter-atomic spacing of $0.225 \mathrm{~nm}$, which agrees well with the value determined from the high angle x-ray scan presented above. The TEM image of the $5 \mathrm{~nm}$ period sample in Figure 4 shows that both layers are crystalline. The in-plane grain size of most of the grains in the $\mathrm{Cu}$ layers (light contrast) is significantly larger than the layer thickness, while the grains in the Ta layers (dark contrast) are comparable or slightly larger. The Ta structure in longer period multilayers appears disordered, although in the $5 \mathrm{~nm}$ period sample, highly textured $002 \mathrm{Ta}$ is observed, as indicated in the high angle X-ray diffraction pattern. Electron diffraction pattern of the $5 \mathrm{~nm}$ period sample in crosssection seems to indicate heteroepitaxial growth of the $111 \mathrm{Cu}$ and the 002 tetragonal Ta phases
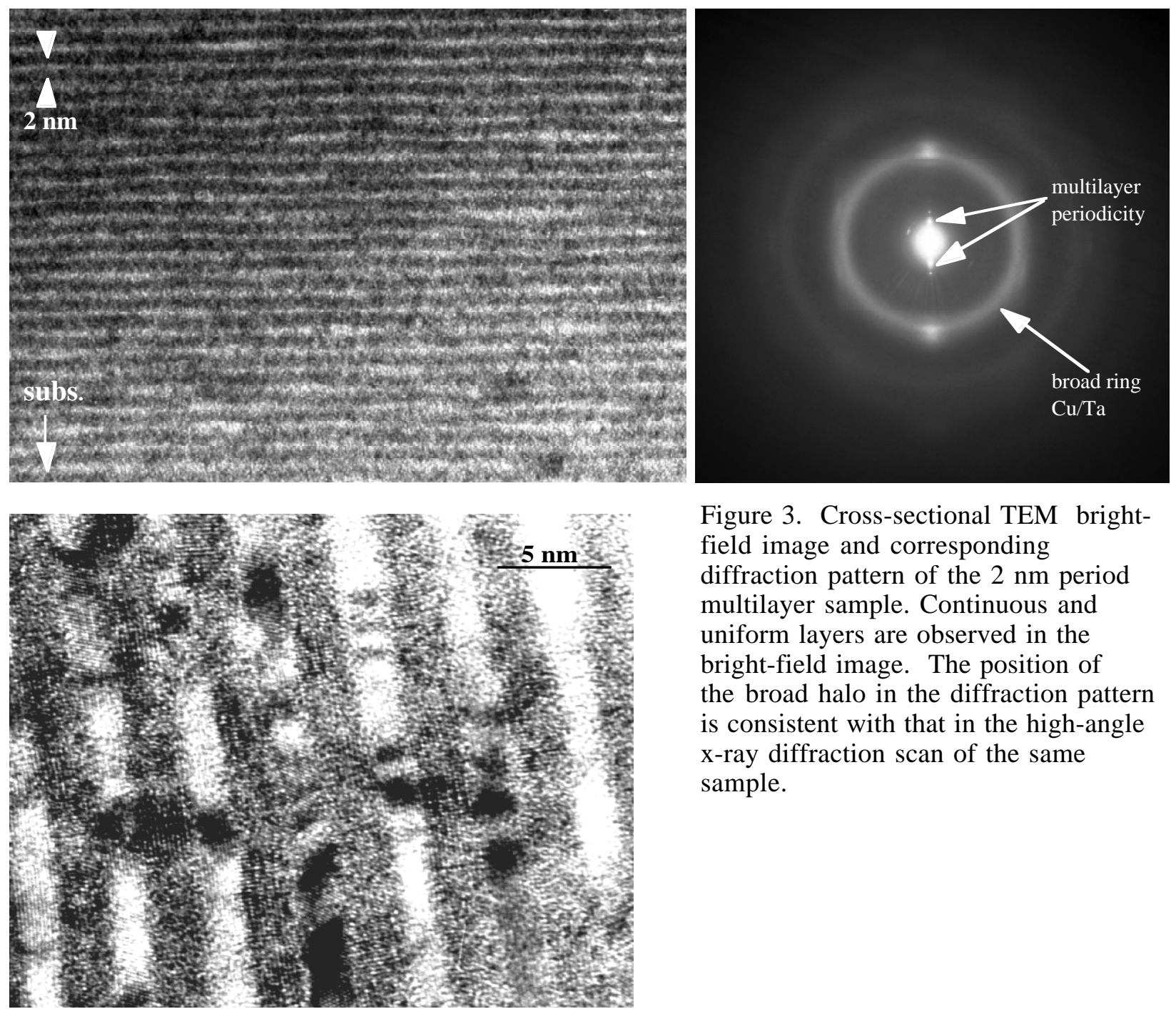

Figure 3. Cross-sectional TEM brightfield image and corresponding diffraction pattern of the $2 \mathrm{~nm}$ period multilayer sample. Continuous and uniform layers are observed in the bright-field image. The position of the broad halo in the diffraction pattern is consistent with that in the high-angle $\mathrm{x}$-ray diffraction scan of the same sample. 
Figure 4. Cross-sectional TEM image of the $5 \mathrm{~nm}$ period sample. The dark layers are Ta and light layers $\mathrm{Cu}$. Evidence of hetero-epitaxial growth across the interfaces is seen at this small period.

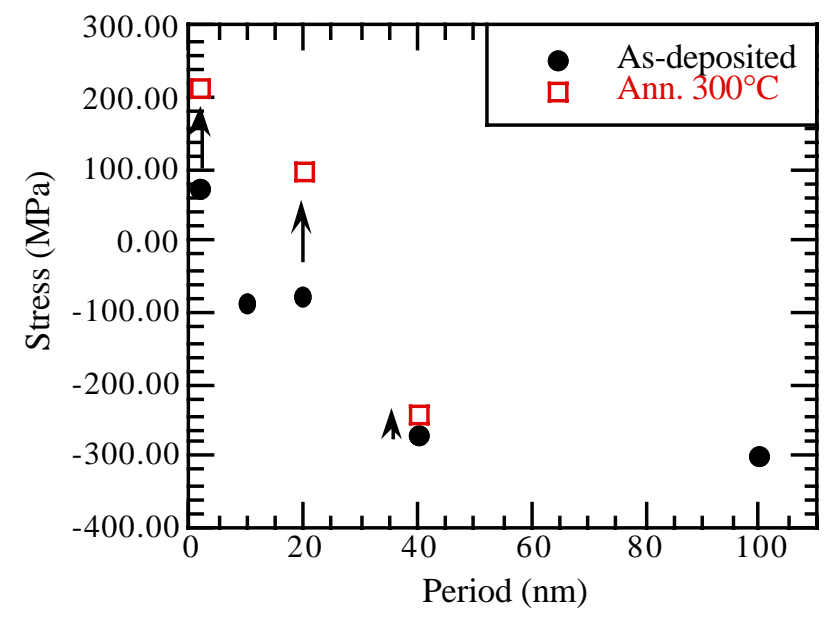

Figure 5. Residual stress in the $\mathrm{Cu} / \mathrm{Ta}$ multilayers. All samples become more tensile upon annealing at $300^{\circ} \mathrm{C}$.

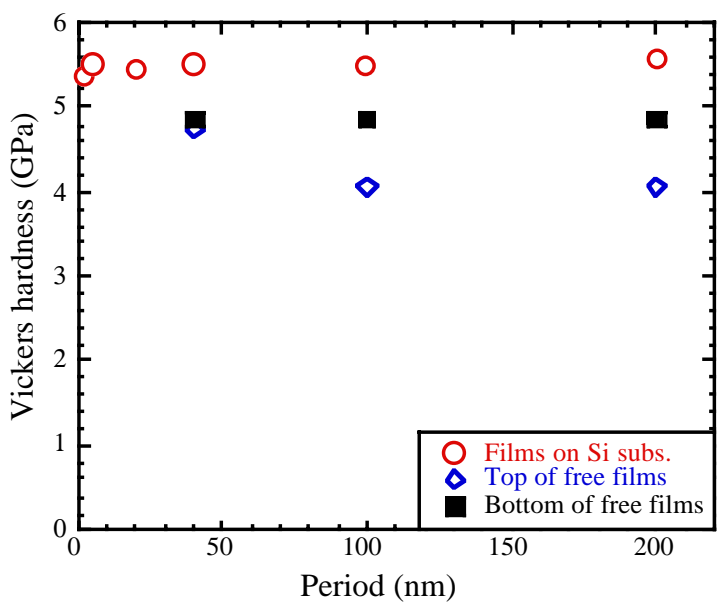

Figure 6. Hardness of the multilayers on the Si substrates and removed from the substrates.

that is supported by the in-plane $330 \beta$-Ta and $220 \mathrm{Cu}$ lattices that are about $7.6 \%$ mismatch with each other. ${ }^{13}$ The diffraction patterns of the longer period multilayers however show more random in-plane structure. This is consistent with the X-ray diffraction data that shows that as the multilayer period increases, other orientations of $\beta$-Ta nucleate and hence the in-plane epitaxial growth is no longer preferred.

The tetragonal structure observed in the Ta layers in the multilayers, and in the elemental film grown on the thermal oxide underlayer, is in agreement with the reported results. The observation of the $\beta-002$ preferred growth orientation in thin Ta layers on $\mathrm{Cu}$ has been associated with an assumed interfacial stress, ${ }^{13}$ which becomes negligible as the thickness increases. A large electronic transfer at the interfaces of the $\mathrm{Cu} / \mathrm{Ta}$ multilayers ${ }^{14}$ in addition may favor the growth of the tetragonal phase. The equilibrium BCC Ta structure has been observed when grown on $\mathrm{Al}^{11}$ or $\mathrm{Cr}^{8}$ underlayer, and is explained by the close lattice match between the underlayer and the $\alpha-\mathrm{Ta}$ structures, which promotes epitaxial growth. ${ }^{13}$ Thick Ta layers in our multilayers has a strongest diffraction peak at the 002 position, in contrast to the growing of the 202/211 $\beta$-Ta peaks and diminishing 002 peak in Ta single layers with thickness larger than $30 \mathrm{~nm}$ grown on a $\mathrm{Cu}$ underlayer. $^{12}$ The $\mathrm{Cu}$ layer sandwich in the multilayers promotes the formation of the $002 \beta$-Ta grains perpendicular to the film layering. Thin film growth and microstructure of $\mathrm{Cu} / \mathrm{Ta}$ multilayers will be presented and discussed in another paper.

\section{$\underline{\text { Residual stress }}$}

The residual stress in the multilayers was found to vary with the multilayer period, with the shortest period multilayer in tension, while all the other multilayers in compression. The stress in the 10 and $20 \mathrm{~nm}$ period multilayer is near $-100 \mathrm{MPa}$, and becomes more compressive with the period to about $-300 \mathrm{MPa}$ for the $100 \mathrm{~nm}$ period. The stress in the elemental Ta film grown on the thermal oxide underlayer is compressive $(-315 \mathrm{MPa})$, while that of the $\mathrm{Cu}$ is almost zero $(-8 \mathrm{MPa})$. Annealing of the multilayers to $300^{\circ} \mathrm{C}$ results in residual stresses that are more tensile than those of 
the as-deposited state. The change in the stress with annealing is larger in smaller period multilayers than in longer period samples. The results of the residual stresses in the $\mathrm{Cu} / \mathrm{Ta}$ multilayers are plotted in Figure 5. The large magnitude of the residual stress present in these multilayers may affect the indentation measurement of the hardness.

\section{$\underline{\text { Hardness }}$}

The Vickers hardness of the multilayers is presented in Figure 6. It is observed that there is little variation in the hardness values, and that no observable enhancement in the hardness with decreasing multilayer period is seen. The average hardness of all the multilayers measured when they are on the silicon substrate is about $5.5 \mathrm{GPa}$, which is between those of the elemental $\mathrm{Cu}(2.2 \mathrm{GPa})$ and $\mathrm{Ta}(11.7 \mathrm{GPa})$ thick films. The hardness of these samples after annealed at $300^{\circ} \mathrm{C}$ was found to be about $5 \%$ higher than that of the respective as-deposited samples. This increase may be related to the change in the stresses in the multilayers.

The multilayers with 40, 100, and $200 \mathrm{~nm}$ period were removed from the silicon substrates, and the hardness was measured both on the top layers, and on the layers near the substrate of the these samples. The hardness of the samples removed from the substrates is lower than that of the multilayers on the silicon substrate under the residual compressive stress state. The hardness of the top layers of the multilayers is less than that of the layers near the substrate, with a smaller difference at smaller periods. These differences may be due to possible larger grain size in the top layers and/or the fact that layers near the top of the samples are not as smooth and flat, whose effects are larger as the multilayers period increases.

The constant hardness of the multilayers with period was unexpected. Constant hardness with period in the range between 2 and 15 nanometers has also been reported in $\mathrm{Cu} / \mathrm{Ag}^{15}$ and $\mathrm{Fe} / \mathrm{Pt}$ multilayers. ${ }^{16}$ In our $\mathrm{Cu} / \mathrm{Ta}$ samples, it is possible that grains in the Ta layers in the longer period multilayers have similar sizes as those in shorter period samples and the grain size effect was not observed. Nucleation of other orientations in the Ta layers in longer period multilayers restrains further grain growth of the 002 grains, which results in the loss of heteroepitaxial growth observed in the $5 \mathrm{~nm}$ period sample. Cross-sectional TEM observation of the $20 \mathrm{~nm}$ period multilayers shows disordered Ta structure, with a high fraction of the grains smaller than the layer thickness.

\section{CONCLUSIONS}

We have reported here a study of the microstructure and mechanical properties of $\mathrm{Cu} / \mathrm{Ta}$ multilayers having periods ranging from 2 to $200 \mathrm{~nm}$. The structure in the $2 \mathrm{~nm}$ period multilayer is predominantly amorphous, while in longer period samples, metastable tetragonal $\beta$-Ta and FCC $\mathrm{Cu}$ were observed. Both $\mathrm{x}$-ray diffraction and TEM results do not indicate any significant changes in the microstructure upon annealing at $300^{\circ} \mathrm{C}$. The residual stress in the $2 \mathrm{~nm}$ period multilayer is tensile, while that in the longer period samples is compressive and increasing with period. Vickers micro-hardness tests reveal little hardness enhancement with period. An average value of about $5.5 \mathrm{GPa}$ in the as-deposited films was observed which increases about 5\% upon annealing. Differences in hardnesses measured on films on substrates and removed from substrates are observed which is attributed to the presence of large residual stresses in films on substrates.

\section{ACKNOWLEDGMENT}

The authors would like to thank J. Alameda, D. Hoffman, and J. Robinson for technical supports, R. Gross and M. Wall for preparing the specimens for TEM observation. Technical discussions with J. Schneider are appreciated. The use of the electron microscopes at the National Center for Electron Microscopy, LBNL is acknowledged. This work was performed under the auspices of 
the U.S. Department of Energy by Lawrence Livermore National Laboratory under contract No. W-7405-ENG-48.

\section{REFERENCES}

1. K. Holloway and P.M. Fryer, Appl. Phys. Lett. 57, 1736 (1990).

2. M. Oda, A. Ozawa, S. Ohki, and H. Yoshihora, Jpn. J. Appl. Phys. 11, 2616 (1990).

3. J.E. Oh, J.A. Woollam, K.D. Aylesworth, D.J. Sellmyer, and J.J. Pouch, J. Appl. Phys. 60, (1986) 4281.

4. T. Sell; H. Mehrer, Zeitschrift fur Metallkunde 88 (11) 842 (1988).

5. U. Mizutani; C.H. Lee, Materials Transactions, JIM 36 (2) 210 (1995).

6. J.A. Thornton and D.W. Hoffman, J. Vac. Sci. Technol. 19, 164 (1977).

7. A.F. Jankowski, A.F. Bionta, and R.M. Gabriele, J. Vac. Sci. Technol. A7, 210 (1989).

8. L.A. Clevenger, A. Mutscheller, J.M.E. Harper, C. Cabral, Jr., and K. Barmak, J. of Appl. Phys. 72 (10) 4918 (1992).

9. L.J. Parfitt; Z.U. Rek; S.M. Yalisove; J.C. Bilello, in Thin Films - Structure and

Morphology, edited by S.C. Moss et al. (Mater. Res. Soc. Proc., 1997) pp. 385-90.

10. Parfitt, L.J.; Karpenko, O.P.; Rek, Z.U.; Yalisove, S.M.; and others, in Thin Films: Stresses and Mechanical Properties, edited by W.W. Gerberich, H. Gao, J.-E. Sundgren, S.P. Baker (Mater. Res. Soc. Proc., 1997) pp. 505-10.

11. T. Koyano; C.H. Lee; T. Fukunaga; U. Mizutani; S. Ikeda, Y. Higuchi, M. Nishikawa, E.

Kita, and A. Tasaki, J. of Mag. and Mag. Mat. 126 (1-3) 161 (1993).

12. R. Hoogeveen; M. Moske; H. Geisler; K. Samwer, Thin Solid Films 275 (1-2) 203 (1996).

13. K.-W. Kwon, C. Ryu, R. Sinclair, and S.S. Wong, Appl. Phys. Lett. 71 (21) 3069 (1997).

14. A.F. Bello, T. Van Buuren, J.E. Klepeis, and T.W. Barbee, Jr., presented at the MRS

Spring Meeting (1998), and to appear in Application of Synchrotron Radiation Techniques to

Materials Science, edited by S. Mini, D. Perry, S. Stock, and L. Terminello.

15. B.J. Daniels, W.D. Nix, and B.M. Clemens, Appl. Phys. Lett. 66 (22) 2969 (1995).

16. S. Hashimoto, M. Ishihara, Y. Sasajima, J. Fac. Eng., Ibaraki University, 43, 75 (1995). 


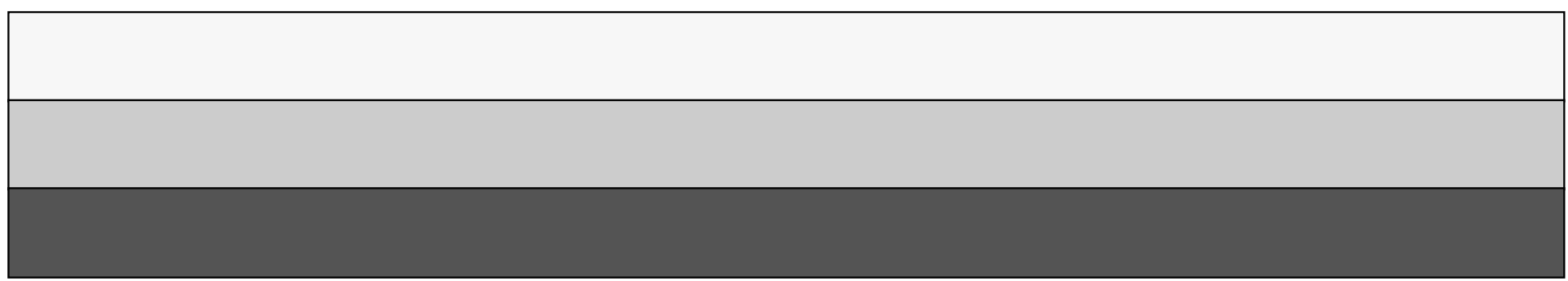

